\title{
Biventricular assist device is an effective rescue device after cardiac surgery
}

\author{
Jamie N Colombo ${ }^{*}$, Peter N Dean ${ }^{1}$ and Mark Roeser ${ }^{2}$ \\ ${ }^{1}$ Department of Pediatrics, Division of Cardiology, University of Virginia, USA \\ ${ }^{2}$ Department of Surgery, Division of Congenital Heart Surgery, University of Virginia, USA
}

\begin{abstract}
For pediatric patients with cardiomyopathy or failing congenital heart disease use of a biventricular assist device is an established mode of care as a bridge-totransplant. However, this technology has not been reported as a rescue mechanism immediately after cardiac surgery. We report 6-month old, 6 kilogram female diagnosed with tetralogy of Fallot, pulmonary atresia and restrictive ventricular septal defect who underwent repair, resulting in biventricular failure immediately following the procedure. Soon after the operation it was apparent she would not recover, and was transitioned to a biventricular assist device.
\end{abstract}

\section{Introduction}

Tetralogy of Fallot (TOF) is the most common form of cyanotic congenital heart disease occurring in 3-6 per 10,000 patients [1]. It is a constellation of structural heart disease including right ventricular outflow obstruction (ranging from pulmonary valve stenosis to complete vessel atresia), right ventricular hypertrophy, a ventricular septal defect (VSD) and overriding aorta. VSDs are usually large secondary to anterior septal malalignment during embryogenesis. Occasionally, VSDs become restrictive from redundant tricuspid valve tissue partially obstructing the defect $[2,3]$. This is associated with higher rates of operative mortality due to elevated right ventricular pressure and decreased function $[2,4]$.

Patients with ventricular dysfunction are more prone to difficulties weaning off cardiopulmonary bypass. If this cannot be accomplished, patients are transitioned to extracorporeal membrane oxygenation (ECMO) for continued cardiac support. When patients are unable separate from ECMO support and are felt to be a good candidate, they are listed for heart transplant. Waiting for an organ can take weeks to months, but ECMO is only life-sustaining for a short period of time, often causing multisystem organ dysfunction and low rates of survival to heart transplant [5].

Biventricular assist devices are a different option if the heart is no longer viable without the short term consequences seen with ECMO, but have not been used as a rescue device following poor outcomes after cardiac surgery. We report on a 6-month old female who underwent TOF repair, developed biventricular failure resulting in placement of a biventricular assist device (BiVAD) as a lifesaving mechanism.

\section{Case report}

The patient was born at 37 weeks gestation and postnatally diagnosed with TOF and pulmonary atresia. Day of life 2 she underwent cardiac catheterization for radiofrequency perforation and pulmonary balloon valvuloplasty. Despite this, saturations remained suboptimal resulting in placement of a modified Blalock Taussig shunt and main pulmonary artery (PA) ligation on day of life 10. Main PA ligation was completed given concern for free pulmonary insufficiency resulting in a circulatory shunt and inadequate cardiac output. She remained stable until five months of age when she was noted to have oxygen saturations in the upper 60s (expected saturations are $75-85 \%$ in shunt dependent lesions). Echocardiogram showed a restrictive VSD due to redundant tricuspid valve tissue and a severely hypertrophied right ventricle with reduced systolic function (Figure 1). Cardiac catheterization additionally demonstrated right and left PA stenosis. She was admitted to the hospital, placed on supplemental oxygen and transferred to our tertiary care facility for surgical repair.

At the time of the repair she was placed on cardiopulmonary bypass with bicaval cannulation. Tricuspid valve tissue causing VSD obstruction was resected and Gortex patch was used to close the VSD. A transannular patch was placed to enlarge the pulmonary valve annulus and right ventricular outflow tract coring was completed to allow for unopposed pulmonary blood flow. Right and left PA stenoses were also enlarged with patch augmentation. A residual atrial septal defect remained. The procedure was complicated by multiple arrhythmias and she was unable separate from cardiopulmonary bypass secondary to left ventricular failure. Right ventricular function remained poor, but was unchanged from preoperative echocardiograms. She was transitioned to ECMO and transferred to the pediatric intensive care unit. By postoperative day (POD) 2 the echocardiogram continued to show bilateral systolic dysfunction and she was requiring escalating medical therapy to maintain hemodynamic stability; ECMO weaning was unsuccessful.

On POD 3 she was listed for heart transplant and on POD 4, she was placed on a continuous flow BiVAD (Figures 2 and 3). Given right ventricle hypertrophy, and a normal, non-dilated left ventricle, Berlin

Correspondence to: Jamie N. Colombo, DO, University of Virginia, 1215 Lee Street, Charlottesville, VA 22903, USA, Tel: 434-924-9119, Fax: 434-9245656, E-mail: jnc2f@virginia.edu

Received: November 20, 2017; Accepted: December 15, 2017; Published: December 19, 2017 
cannulae were places in the left and right atrium following atrial septal defect closure. Outflow cannulae were attached to the native ascending aorta and pulmonary artery transannular patch. The transannular patch was then ligated proximal to the cannula to prevent backflow of blood moving through the ventricular assist device as no pulmonary valve was present. Next, bypass was weaned onto biventricular continuous flow devices. The left ventricular assist device was run at $150 \mathrm{cc} /$ minute of higher flow to make up for the increased pulmonary venous return secondary to multiple collateral vessels present after her prolonged hypoxic state. She tolerated the procedure well, but continued to suffer from persistent ventricular arrhythmias.

The following day the patient had increased pulmonary edema on chest $\mathrm{x}$-ray, the left ventricular assist device rate was increased to have a $200 \mathrm{cc} /$ minute difference between the right and left rates. This allowed blood in the 'left heart' to move more quickly compensating for increased pulmonary venous return and thus improving edema.

POD 7 she was transitioned to a Berlin Heart (pulsatile, long term BiVAD) with continued asynchronicity in flow rate. POD 11 she

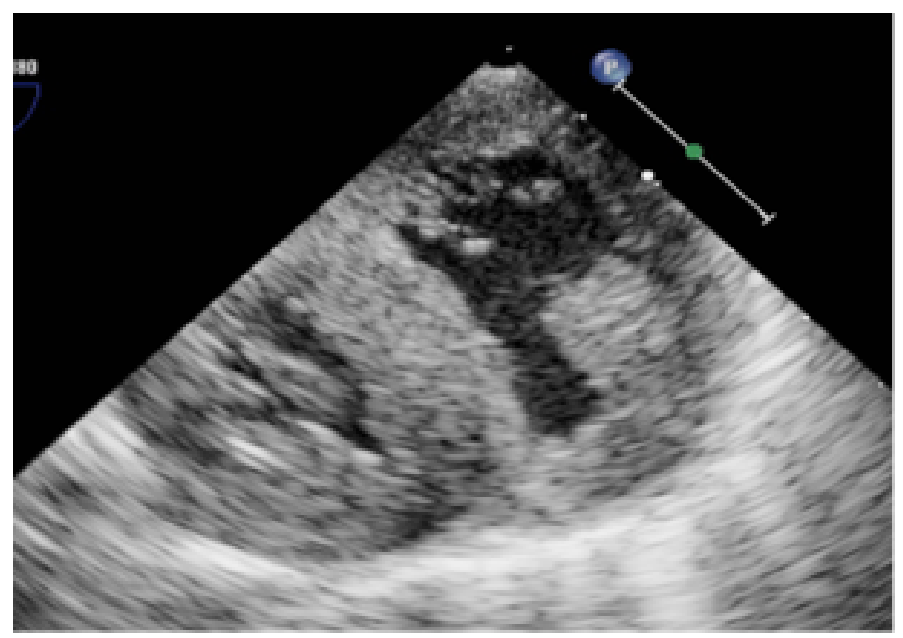

Figure 1. Echocardiogram following tetralogy of Fallot repair showing biventricular hypertrophy.

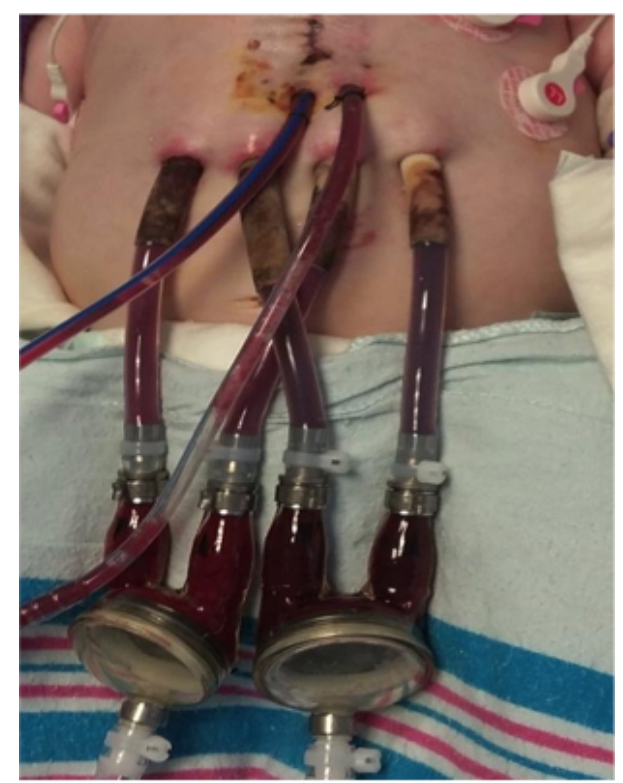

Figure 2. Postoperative day 8 with bilateral biventricular assist device in place.

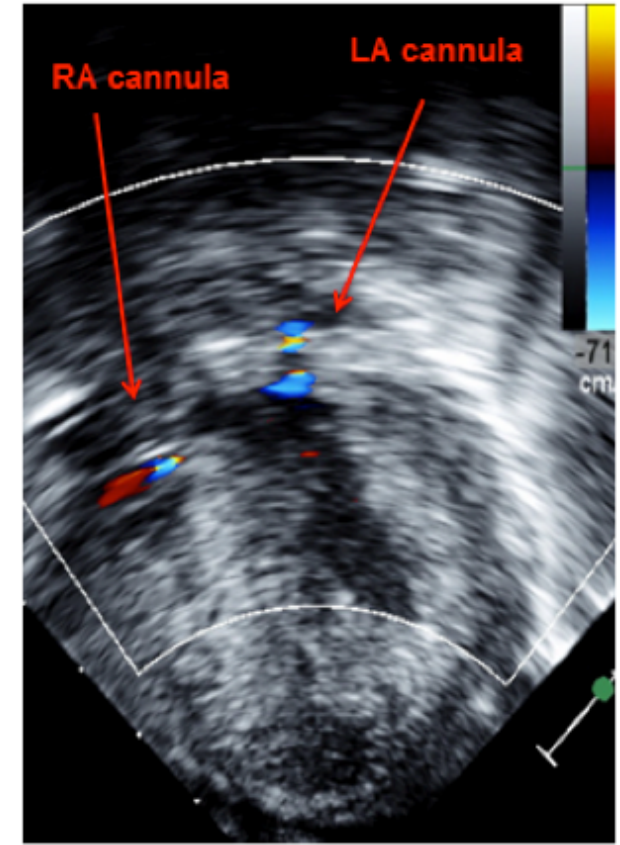

Figure 3. Transgastric transesophageal echocardiogram demonstrating appropriate decompression of the ventricles using continuous flow biventricular ventricular assist devices. Inflow cannulas visualized in the right and left atrium.

successfully underwent cardiac transplant. She was extubated 3 days later and was discharged home 2 weeks after transplant. She is now over a year post transplant, with normal development and no signs of rejection.

\section{Discussion}

Ventricular assist devices are routinely used as a bridge to transplant in end-stage heart failure [5,6], but this is the first case to use a ventricular assist device as a rescue device following a cardiac surgery. Until now, ECMO has been the mainstay for supporting the heart following cardiac surgery due to inability to wean cardiopulmonary bypass, postoperative low cardiac output syndrome or heart failure secondary to cardiac arrest. However, it is well established that ECMO is associated with a high risk of mortality with up to $53 \%$ in postoperative ECMO use and $57 \%$ mortality when used in patients with complex congenital heart disease [7]. Additionally, with ECMO multiple complications can arise, such as bleeding, infection, neurologic complications and multisystem organ failure $[6,7]$. ECMO is only a short-term solution to support the heart, and overall survival to discharge is low, between $35-53 \%$ [5-7]. Mortality rate increases to $50 \%$ for patients on ECMO waiting for a heart transplant [6].

Traditionally, a ventricular assist device has been used as a bridgeto-transplant after cardiac failure is deemed irreversible [8-10]. Only recently have ventricular assist devices been available in small children, $<10$ kilograms, and its use remains rare $[8,9]$. The use of a $\mathrm{BiVAD}$ is even more rare as it has been associated with poor clinical outcomes including renal failure, neurologic compromise and high mortality [11]. Ventricular assist devices are more commonly used in children with cardiomyopathy or myocarditis rather than children with congenital heart disease $[8,11-14]$. This is likely multifactorial as patients with congenital heart disease are higher risk for morbidity and mortality when it comes to ventricular assist device placement [8]. Often times they have a disruption in the normal inflow and outflow patterns of the heart necessary for placement of a ventricular assist 
device $[13,15]$. Ventricular assist device size must also be considered in patients with single ventricle physiology, as it must support both systemic and pulmonary blood flow $[9,15]$.

Our patient's diagnosis of tetralogy of Fallot with pulmonary atresia created many factors that needed to be considered with BiVAD placement. First, the patient had undergone a transannular patch so no pulmonary valve was present, therefore, when the outflow cannula was sewn into the pulmonary artery, blood would not be able to flow forward given free insufficiency. Tying off the main pulmonary artery to prevent backflow of blood solved this problem.

Cannula placement was also a challenge given chronically elevated right ventricular systolic pressure causing hypertrophy and decreased cavity size. This prevented placement of a right ventricular inflow cannula. Left ventricle morphology was normal (i.e. it was not dilated as is the case with most cardiomyopathies), which was also not amenable to cannula placement. Inflow cannula for both the right and left side were placed into bilateral atria allowing for unrestricted blood flow. While previously reported in the literature, this mechanism has been associated with a higher rate of neurologic injury, especially in small patients, which led to now, routine apex cannulation [9]

Finally, given our patient's prolonged hypoxic state prior to her initial repair she developed many aortopulmonary collateral vessels leading to increased blood flow to the lungs. This was managed by allowing the left ventricular assist device to flow at a slightly higher rate compared to the right ventricular assist device. As such, she did not development pulmonary congestion.

While the cause of cardiac compromise in our patient is unclear, the evidence of prolonged cardiac dysfunction, inability to wean from ECMO, and unrelenting lethal arrhythmias made a transplant the only option. Further investigation to clarify the reason for cardiac compromised was felt to be unnecessary as multiple echocardiograms failed to define a reversible cause and additional invasive procedures would only increase mortality risk. Thus, our patient was listed for heart transplant and a BiVAD was placed. To our knowledge this is the only incidence of a BiVAD being used as a successful rescue mechanism following heart failure in a pediatric patient after surgical repair. On the basis of our experience a ventricular assist device could be used in the future as more than just a bridge to transplant, but rather as a rescue device in the setting of a complicated surgical outcome.

\section{References}

1. Gerrah R, Turner ME, Gottlieb D, Quaegebeur JM, Bacha E (2015) Repair of Tetralogy of Fallot in Children Less Than $4 \mathrm{~kg}$ Body Weight. Pediatr Cardiol 36: 1344-1349. [Crossref]

2. Flanagan MF, Foran RB, Van Praagh R, Jonas R, Sanders SP (1998) Tetralogy of fallot with obstruction of the ventricular septal defect: Spectrum of echocardiographic findings. J Am Coll Cardiol 11: 386-395. [Crossref]

3. Soni MR, Bohara DA, Mahajan AU, Nathani PJ (2012) Tetralogy of Fallot with restrictive ventricular septal defect by accessory tricuspid leaflet tissue. Indian Heart $J$ 64: 412-415. doi:10.1016/j.ihj.2012.06.009. [Crossref]

4. McBrien A, Kirk R, Crossland DS (2011) Tetralogy of fallot with restrictive ventricular septal defect. Pediatr Cardiol 32: 117-118. [Crossref]

5. BarZiv SMP, McCrindle BW, West LJ, Edgell D, Coles JG, et al. (2007) Outcomes of Pediatric Patients Bridged to Heart Transplantation from Extracorporeal Membrane Oxygenation Support. ASAIO J 53: 97-102. [Crossref]

6. Jeewa A, Manlhiot C, McCrindle BW, Van Arsdell G, Humpl T, et al. (2010) Outcomes With Ventricular Assist Device Versus Extracorporeal Membrane Oxygenation as a Bridge to Pediatric Heart Transplantation. Artif Organs 34: 1087-1091. [Crossref]

7. Thiagarajan RR (2016) Extracorporeal Membrane Oxygenation for Cardiac Indications in Children. Pediatr Crit Care Med 17: 155-159. [Crossref]

8. Almond CS, Morales DL, Blackstone EH, Turrentine MW, Imamura M, et al (2013) Berlin heart EXCOR pediatric ventricular assist device for bridge to heart transplantation in US children. Circulation 127: 1702-1711. [Crossref]

9. Brancaccio G, Amodeo A, Ricci Z, Morelli S, Gagliardi MG, et al. (2010) Mechanical Assist Device as a Bridge to Heart Transplantation in Children Less Than 10 Kilograms. Ann Thorac Surg 90: 58-62. [Crossref]

10. Fraser CD, Jaquiss RDB (2013) The berlin heart EXCOR pediatric ventricular assist device: History, north american experience, and future directions. Ann N Y Acad Sci 1291: 96-105. [Crossref]

11. Zafar F, Jefferies JL, Tjossem CJ, Bryant R 3rd, Jaquiss RD, et al. (2015) Biventricular Berlin Heart EXCOR pediatric use across the united states. Ann Thorac Surg 99: 13281334. [Crossref]

12. Prêtre R, Häussler A, Bettex D, Genoni M (2008) Right-Sided Univentricular Cardiac Assistance in a Failing Fontan Circulation. Ann Thorac Surg 86: 1018-1020. [Crossref]

13. Brancaccio G, Gandolfo F, Carotti A, Amodeo A (2013) Ventricular assist device in univentricular heart physiology. Interact Cardiovasc Thorac Surg 16: 568-569. [Crossref]

14. Gandhi SK, Huddleston CB, Balzer DT, Epstein DJ, Boschert TA, et al. (2008) Biventricular assist devices as a bridge to heart transplantation in small children. Circulation 118: S89-S93. [Crossref]

15. Mackling T, Shah T, Dimas V, Guleserian K, Sharma M, et al. (2012) Management of Single-Ventricle Patients With Berlin Heart EXCOR Ventricular Assist Device: SingleCenter Experience. Artif Organs 36: 555-559. [Crossref]

Copyright: (C2017 Colombo JN. This is an open-access article distributed under the terms of the Creative Commons Attribution License, which permits unrestricted use, distribution, and reproduction in any medium, provided the original author and source are credited. 